\title{
AQUISIÇÃO \\ DE INGLÊS \\ COMO L3 POR SURDOS \\ BRASILEIROS USUÁRIOS \\ DE LIBRAS COMO L1: \\ CONSIDERAÇÕES \\ TEÓRICO-PEDAGÓGICAS
}

\section{ADQUISICIÓN DEL INGLÉS COMO L3 POR SORDOS BRASILEÑOS USUARIOS DE LIBRAS COMO L1: CONSIDERACIONES TEORICO-PEDAGÓGICAS}

\author{
ACQUISITION OF ENGLISH AS L3 BY BRAZILIAN DEAF USERS OF LIBRAS AS L1: \\ THEORETICAL AND PEDAGOGICAL IMPLICATIONS
}

Maria Clara Corsini da Silva*
Colégio Militar de Porto Alegre

Lilian Cristine Hübner

PUCRS | CNPq

\begin{abstract}
RESUMO: Este artigo tem como objetivo discutir questões metodológicas relacionadas à aquisição de terceira língua (L3) por sujeitos surdos usuários nativos da Libras (L1), do Português Brasileiro como segunda língua (L2) e aprendizes de inglês ou outra língua adicional como terceira língua (L3), a partir de uma revisão de literatura. Embora a Libras tenha sido oficializada no Brasil pela Lei n 10.436 de 2002, os estudos que investigam a aquisição de línguas adicionais por esses aprendizes, em especial de uma L3, são ainda incipientes, assim como são os debates sobre como se dá o seu processo de ensino e aprendizagem. Destaca-se a ênfase em métodos visuais para o alcance da literacia por aprendizes surdos e na associação entre a língua alvo e a Libras.

PALAVRAS-CHAVE: Libras. Bilinguismo Intermodal. Multilinguismo. Leitura. Escrita. Surdos.
\end{abstract}

\footnotetext{
Doutora em Letras - Linguística pela PUCRS e professora de Língua Inglesa para surdos e ouvintes. Professora de Língua Inglesano Colégio Militarde Porto Alegre, RS. E-mail: claracorsini04@gmail.com.

Doutora em Letras pela UfSC, professora da Escola de Humanidades da PUCRS nos Cursos de Letras Inglês e Português e no PPG Letras - Linguística da PUCRS. Bolsista de Produtividade em Pesquisa CNPq 3 . E-mails: lilian.hubner@pucrs.br; lilian.c.hubner@gmail.com
} 
RESUMEN: Este artículo tiene como objeto discutir cuestiones metodológicas para la adquisición de una tercera lengua (L3) por sujetos sordos usuarios nativos de Libras (Lengua Brasileña de Señales) (L1), de Portugués Brasileño como segunda lengua (L2) y aprendices de inglés u otra lengua adicional como tercera lengua (L3), desde una revisión de literatura. Aunque la Libras haya adquirido carácter oficial en Brasil por la Ley n 10.436/2002, los estudios que investigan la adquisición de las lenguas adicionales por esos aprendices, en especial de una L3, son todavía incipientes, así como lo son los debates sobre cómo se da su proceso de enseñanza y aprendizaje. Se destaca el énfasis en métodos visuales para lograr la lectoescritura de los aprendices sordos y en la importancia de la asociación entre el idioma de destino y la Libras.

PALABRAS CLAVE: Libras. Bilingüismo Intermodal. Multilingüismo. Lectura. Escrita. Sordos.

ABSTRACT: This article aims at discussing methodological aspects related to the acquisition of a third language (L3) by deaf native speakers of Libras (Brazilian Sign Language), of Brazilian Portuguese as second language (L2) and learners of English or other additional language as third language (L3), by means of a literature review. Although Libras has become official language in Brazil by Law $n$. 10.436 in 2002, studies on the acquisition of additional languages by these learners, in special of an L3, are still incipient, as are the debates on how additional languages teaching and learning processes take place. Emphasis should be given to visual methods to develop literacy with deaf learners and to the association between the target language and Libras.

KEYWORDS: Libras. Intermodal Bilingualism. Multilingualism. Reading. Writing. Deaf.

\section{INTRODUÇÃO}

No cenário das pesquisas sobre aquisição da linguagem não é raro encontrar uma vasta bibliografia tendo como objeto de estudo a aquisição ${ }^{1}$ bilíngue de línguas orais. Entretanto, pesquisadores como Cenoz (2000), Blank e Zimmer (2009), entre outros, destacam que estudos que investiguem a aquisição de uma terceira língua (L3) ainda são incipientes não apenas no Brasil como em grande parte dos outros países, evidenciando-se, assim, um descompasso entre estudos da aquisição bilíngue e multilíngue. Esse contraste torna-se ainda maior quando é investigada a aquisição multilíngue entre línguas de modalidades diferentes, ou seja, línguas expressas por formas distintas, como as línguas oral-auditivas e as línguas de sinais.

No que tange às pesquisas sobre aquisição de língua adicional oral por surdos, na forma escrita, ainda se observa a predominância de pesquisas direcionadas à aquisição apenas de uma L2, seja no cenário nacional ou internacional. No Brasil, são poucos os trabalhos voltados para o estudo da aquisição de L3 por surdos. As pesquisas de Oliveira (2007), Sousa (2015), Brito (2010), Rubio (2010), Medeiros (2011), Silva e Hübner (2015), Tavares e Oliveira (2014) e Coura (2017), entre outras, despontam como pioneiras nesse campo de estudo. Entretanto, a maior parte dessas pesquisas não enfoca a aquisição da Língua Inglesa (doravante $\left.\mathrm{LI}^{2}\right)$ per se, em estudos que forneçam dados empíricos para uma análise objetiva das produções dos alunos, aprendendo LI como L3, e que possam oferecer reflexões e práticas pedagógicas significativas para os professores. As investigações sobre o assunto, geralmente, tratam de questões como: os modelos de inclusão escolar, como apresenta Oliveira (2007), as políticas públicas, como também as crenças de professores e alunos sobre o ensino de uma L3, igualmente apresentado por Oliveira (2007). Sousa (2015), por sua vez, discute as estratégias de comunicação na escrita de surdos e Brito (2010) analisa o papel do intérprete de Libras no ambiente escolar. Rubio (2010) traz à discussão a escola inclusiva onde surdos e ouvintes estão inseridos no mesmo espaço e Medeiros (2011) analisa os aspectos legais na aquisição de uma L3. O papel das transferências léxico-semânticas entre línguas de modalidades diferentes é analisado por Silva e Hübner (2015). Ainda, o artigo de revisão de Bastos e Hübner (2020) aborda questões atinentes aos processos de compreensão leitora e de produção escrita em LI como L3, igualmente tratando, dentre outros temas, da questão da transferência das línguas previamente aprendidas (Libras e LP) nesses processos. Assim como as pesquisas sobre os processos de aquisição num viés psicolinguístico são escassas, da mesma forma estudos sobre métodos pedagógicos adequados para o ensino de uma ou duas línguas adicionais orais na forma escrita para aprendizes surdos são muito incipientes ainda.

\footnotetext{
${ }^{1}$ Não é feita nesse trabalho a distinção entre "aquisição" e "aprendizagem”, proposta por Krashen (1982), nem a distinção entre os termos "língua estrangeira", "segunda língua (L2)", "língua adicional" e "língua-alvo", logo esses termos poderão ser utilizados de forma intercambiável nesse trabalho.

${ }^{2}$ Neste artigo, trataremos em especial da Língua Inglesa como L3 para surdos, porém a discussão pode ser estendida a outras línguas adicionais, como a Língua Espanhola, amplamente ensinada no contexto brasileiro como L2 ou L3, em especial para ouvintes.
} 
Diante do exposto, o presente trabalho pretende abordar questões pedagógicas atinentes ao ensino de L3 para surdos, a partir da discussão de dados empíricos e de reflexões teóricas. O artigo encontra-se estruturado a partir destas três perguntas geradoras: 1) Como se caracteriza o estudante surdo aprendiz da escrita de línguas adicionais (L2) de modalidades orais? 2) Quais os desafios para o ensino-aprendizagem da escrita de uma L3 (multilinguismo) de modalidade oral para o aprendiz surdo? e 3) A partir dos desafios existentes no processo de ensino-aprendizagem de uma L3 escrita por surdos, quais as implicações pedagógicas para o ensino desses sujeitos?

\section{COMO SE CARACTERIZA O ESTUDANTE SURDO APRENDIZ DE LÍNGUAS ADICIONAIS (L2) DE MODALIDADE ORAL?}

Os trabalhos sobre o bilinguismo, na sua grande maioria, têm como objeto de estudo as línguas orais e priorizam pesquisas com sujeitos ouvintes. Entretanto, com o reconhecimento das línguas de sinais como línguas naturais, tem havido um crescente interesse em se pesquisar a aquisição das línguas de sinais (LS) e orais (especialmente no meio escrito) por sujeitos surdos. No Brasil, o atual interesse em se investigar a LS deve-se igualmente ao fato de essa língua encontrar amparo oficial na legislação que reconhece a Libras como meio legal de comunicação e expressão, constituindo a segunda língua oficial de nosso país. Essa situação linguística está prevista na Lei da Libras, Lei no 10.436 (BRASIL, 2002), e foi regulamentada no Decreto nº 5.626 (BRASIL, 2005).

Se bilíngue é o indivíduo que aprendeu e utiliza duas línguas sendo capaz de "funcionar" nas línguas adquiridas de acordo com as necessidades propostas, como define Grosjean (1996), as pessoas surdas que sinalizam em sua LS e usam a língua oral majoritária (na forma escrita) são consideradas como tal. De fato, o sujeito surdo escolarizado é caracterizado como bilíngue ${ }^{3}$, pois utiliza tanto a sua LS (L1) como a língua oral majoritária (L2), preferencialmente, na forma escrita por ser mais acessível à sua realidade sensorial. Esse tipo de bilinguismo é denominado de bilinguismo intermodal, pois inclui línguas que são percebidas e expressas por canais distintos (fala-sinal). Por outro lado, o bilinguismo que envolve duas línguas comunicadas por intermédio do mesmo canal, sejam duas línguas orais ou de sinais, é caracterizado como unimodal ou monomodal, como esclarecem Quadros, Lillo-Martin e Chen Pichler (2010)

Na verdade, o bilinguismo intermodal utilizado pelo sujeito surdo não constitui uma opção, mas uma necessidade para sua inserção social, pois a língua majoritária da sociedade (L2) difere de sua língua materna (L1). Sabe-se que grande parte do que se aprende é veiculado pela língua escrita, motivo pelo qual o sucesso acadêmico e profissional do surdo depende, em grande parte, do conhecimento da língua oral na sua forma escrita.

No que se refere à condição bilíngue do surdo, existem peculiaridades que o distinguem de seus pares ouvintes. Enquanto a criança ouvinte está exposta à sua L1 desde o nascimento, essa não é a norma para a criança surda. Pesquisas como as de Quadros (1997) demonstram que os surdos, em sua grande maioria, são filhos de pais ouvintes, sendo que geralmente esses pais não têm conhecimento da LS, língua que terá status de L1 para seu filho. Esse fato pode tornar a aquisição da LS tardia, neste caso gerando atrasos linguísticos significativos e muita variação no nível de competência linguística entre a LS (L1) e a língua oral (L2).

De acordo com pesquisadores como Plaza Pust (2005), a variação no nível de proficiência da L1 está relacionada a fatores como a idade em que a perda auditiva é detectada e o status linguístico dos pais (se ouvintes ou surdos), pois surdos filhos de pais surdos adquirem a LS mais rapidamente do que crianças surdas filhas de pais ouvintes. Outro fator que pode gerar maior demora na aquisição da L1 está relacionado ao ensino que a criança/jovem surdo recebe. Muitas vezes, segundo Plaza Pust (2005), a instrução escolar desses sujeitos consiste no treinamento da fala e da audição em vez de ser ministrada em sua própria língua materna. Ademais, muitas vezes as escolas que trabalham com ouvintes e surdos simultaneamente não estão preparadas para oferecer uma educação bilíngue de qualidade que contemple as especificidades educacionais desses alunos.

${ }^{3} \mathrm{O}$ bilinguismo de indivíduos surdos também pode envolver o uso de duas línguas de sinais, porém essa forma é menos comum na comunidade surda brasileira e tem sido objeto de poucas investigações. 
Além dos fatos elencados acima, é relevante mencionar que o aprendiz surdo utiliza uma língua materna que não tem representação escrita ${ }^{4}$ no sentido de ser amplamente utilizada pela comunidade surda, porém quando ele ingressa na escola, será necessário aprender a ler e a escrever uma língua (L2) de sistema de escrita alfabético a qual ele não ouve e que, na maioria das vezes, não conhece. O conhecimento da L2 e o decorrente domínio da escrita nessa língua não ocorre de maneira natural para as pessoas surdas. A língua que elas percebem e utilizam de maneira natural é a língua de sinais, que constitui sua L1. Nesse contexto no qual os usuários de Libras não têm domínio de sua L1 escrita e onde necessitam da L2 para poderem se expressar de forma escrita, é natural que encontrem dificuldades tanto na escrita quanto na leitura da L2.

Toda a aprendizagem do sujeito surdo passa pela percepção visual e, para compensar a falta do sentido da audição, os surdos valemse exclusivamente da visualização para significar e se apropriar de novos conhecimentos ${ }^{5}$. Dessa forma, por não ouvir, o surdo apoiase exclusivamente no aspecto visual da escrita como um facilitador do processo de aquisição de uma língua adicional. Na verdade, a característica do aprendiz surdo de recorrer a estratégias visuais relacionando-as à sua LS se aplica tanto para a LP como para a LI, bem como para qualquer outra disciplina escolar que o surdo esteja aprendendo.

Tendo em vista as peculiaridades inerentes à aquisição de L2 (ou L3) por sujeitos surdos usuários de LS, tornam-se evidentes a complexidade e os desafios da aquisição de uma L2 escrita por esses indivíduos. Ademais, nesse contexto, ainda devem ser consideradas todas as particularidades atinentes à aquisição de uma língua adicional como a idade de aquisição e a frequência de uso da L2 (ou L3), o tipo de ensino (formal, informal), o método de ensino, a motivação do aluno, as transferências entre as línguas envolvidas (BASTOS; HÜBNER, 2020), para mencionar alguns fatores presentes na aquisição de um outro sistema linguístico.

Por fim, é importante salientar que o surdo, usuário de duas línguas, constitui-se como um indivíduo bicultural, como esclarece Perlin (1998), uma vez que convive, no mesmo país, com duas línguas e culturas distintas: a Libras, sua L1, que lhe insere em uma cultura própria (cultura surda), e a LP, como L2, língua oral majoritária (cultura ouvinte). Autores como Perlin (1998) afirmam que os surdos têm características culturais que marcam o seu modo de ser, de sentir e de se relacionar com o mundo, e a cultura da comunidade surda se traduz na forma visual. A cultura surda é um meio de afirmação coletivo dos surdos, que, como grupo minoritário, compartilha características comuns, sendo a LS um dos elementos essenciais na formação dessa identidade. O ensino de línguas adicionais deve respeitar o status da Libras como a língua majoritária na cultura surda brasileira, num sentido de não a subtrair, e sim, adicionar outras línguas como ferramentas de conhecimento e integração em outras culturas.

A pergunta geradora seguinte tratará das dificuldades encontradas por professores de línguas adicionais ministrando aulas para surdos.

\section{QUAIS OS DESAFIOS PARA O ENSINO-APRENDIZAGEM DE UMA L3 (MULTILINGUISMO) DE MODALIDADE ORAL PARA O APRENDIZ SURDO?}

Considerando as características do bilinguismo intermodal e as dificuldades intrínsecas à aquisição escrita de uma L2 de modalidade oral-auditiva pelo sujeito surdo, pode-se relacionar uma série de desafios presentes no processo de ensino-aprendizagem de uma terceira língua oral no meio escrito. Como mencionado na seção anterior, o sujeito surdo usuário de sua LS e escolarizado na L2 majoritária de seu país é considerado bilíngue. No Brasil, além da Libras (L1) e da LP (L2), faz parte do currículo escolar da Educação Básica o ensino de uma Língua Estrangeira Moderna (inglês ou o espanhol), línguas que constituem uma L3 no contexto educacional do aprendiz surdo brasileiro. A aprendizagem da LI representa um direito e uma conquista, pois na sociedade atual, em

\footnotetext{
${ }^{4}$ As LS apresentam sistemas de representação gráfica, que são uma forma de ler e escrever os sinais, como o Sign Writing e a ELiS (Escrita de Língua de Sinais), porém esses sistemas não são amplamente utilizados pela(s) comunidade(s) surda(s) brasileira(s).

${ }^{5}$ Vale destacar que a utilização exclusiva da visualização para apropriar-se de novos conhecimentos se dá nos casos de surdos sem resquícios auditivos ou surdos severos-profundos, pois os surdos com surdez leve e moderada conseguem fazer alguma relação som-escrita e estabelecer aprendizagens por meio de experiências auditivas/sonoras.
} 
que as pessoas convivem em um mundo cada vez mais interconectado, é inegável a importância do conhecimento de uma língua adicional, notadamente a LI, que assume status de língua franca.

Ademais, existem os aspectos legais que amparam o direito do surdo de aprender uma L3. A LDB (Lei nº 9394/96, artigo 36, inciso III) estabelece que no Ensino Médio será incluída uma língua estrangeira moderna como disciplina obrigatória. A referida legislação sofreu alterações no ano de 2016 com a LDB (Lei n ${ }^{\circ}$ 9.394/2016), que determinou a obrigatoriedade da oferta da LI a partir do $6^{\circ}$ ano do Ensino Fundamental e no Ensino Médio. Quanto aos alunos com necessidades especiais, a LDB prescreve, em seu artigo 59, capítulo I, que os sistemas de ensino assegurarão a esses educandos "currículos, métodos e técnicas, recursos educativos e organização específica para atender às suas necessidades” (BRASIL, 1996).

Em nosso país, e igualmente no cenário internacional, ainda são raros os estudos sobre a aquisição de L3 por surdos, pois a maioria dos estudos investiga a aquisição de línguas orais por ouvintes bilíngues monomodais. No Brasil, as pesquisas de Sousa (2015), Medeiros (2011), Tavares e Oliveira (2014), Pereira (2015), Silva e Hübner (2015) e Coura (2017), entre outras, despontam como inéditas nesse campo de estudo e oferecem referências teóricas relevantes para os estudos de L3 por sujeitos surdos.

Entre os desafios encontrados para a implementação do ensino de uma L3, verifica-se, em muitos espaços educacionais, resistência de educadores que acreditam que o aluno surdo já enfrente muitas dificuldades em adquirir a LP (L2), não havendo, portanto, necessidade do aprendizado de um terceiro sistema linguístico. Como o surdo não tem acesso ao sistema fonológico das línguas oral-auditivas, muitos professores acreditam que o ensino de uma L3 oral (na forma escrita) é desnecessário e ineficaz, pois sem acesso à oralidade de uma língua não seria possível o aprendizado de sua escrita. As crenças desses professores demonstram falta de formação desses profissionais, que baseiam suas concepções pedagógicas na relação fala-escrita, ou seja, na visão de que o ensino de uma língua oral só é possível para ouvintes.

$\mathrm{Na}$ verdade, no contexto educacional brasileiro, segundo nosso conhecimento, é praticamente inexiste a formação teóricometodológica adequada para professores de LI para surdos nos cursos de graduação de Letras. No ambiente escolar, seja em escolas que trabalham com educação inclusiva, seja em escolas bilíngues para surdos, os professores de LI se veem sem o aporte necessário que os oriente a ministrarem suas aulas de forma adequada, conhecendo e respeitando as particularidades dos alunos surdos. $\mathrm{Na}$ licenciatura para o ensino de línguas adicionais, a formação acadêmica que os professores de LI recebem é majoritariamente voltada a alunos ouvintes. Por esse motivo, os educadores, ao iniciarem seu trabalho com a educação de surdos, demonstram desinformação e desconhecimento acerca da surdez e de suas peculiaridades, incluindo como se dá o processo de aquisição de línguas por esses aprendizes.

Outro desafio no ensino da LI para alunos surdos refere-se aos materiais didáticos. Há uma escassez de materiais específicos para o ensino de LI para surdos, com conteúdo e formatos adequados à característica bilíngue intermodal desses alunos, apesar da relevância do domínio da LI no atual cenário e do respeito às diferenças das pessoas com necessidades especiais. Consequentemente, conforme Sousa (2015), os professores em sua maioria preparam suas aulas e elaboraram seus materiais de forma intuitiva, baseados em sua experiência didática, adaptando materiais de alunos ouvintes ou elaborando seus próprios instrumentos e recursos de ensino.

Os espaços escolares em que os surdos estão inseridos não contemplam por vezes as especificidades desses sujeitos. A educação inclusiva, defendida por lei (LDBN 9394/96), tem a proposta de inserir alunos surdos e ouvintes no mesmo ambiente educacional, porém sabe-se que, na prática, há diversos fatores que acarretam problemas para o aprendizado do aluno surdo. Nesse ambiente onde a língua primária é a LP, interagem o professor e alunos ouvintes - que, em geral, desconhecem a LS - uma minoria de alunos surdos e o intérprete de Libras, que faz a mediação entre ouvintes e surdos. Observando-se a realidade escolar das aulas de línguas adicionais na educação inclusiva, fica evidente que, em geral, a metodologia dos professores é direcionada aos ouvintes, e há professores que enfatizam os aspectos orais da língua, ignorando, assim, as necessidades especiais dos alunos surdos, como discutem Oliveira (2007) e Bastos e Hübner (2020). Contudo, existem as escolas bilíngues para surdos, que oferecem as condições ideias para esses alunos. Nesse contexto, é priorizada a Libras como L1, a LP como L2, a LI como L3, e as demais disciplinas são ministradas em Libras. Como destaca Oliveira (2007), nas escolas bilíngues para surdos há a valorização da LS, pois ela é a língua prioritária que 
estabelece a relação entre o aluno e os novos conhecimentos em diferentes disciplinas escolares. No entanto, em termos nacionais, essas instituições de ensino ainda são em número bastante reduzido ou mesmo inexistentes em muitas cidades. Na rede pública estadual do Rio Grande do Sul existem cinco escolas bilíngues para surdos (ASSEMBLEIA LEGISLATIVA DO RIO GRANDE DO SUL, 2019); as demais instituições oferecidas são as escolas mistas, ou seja, escolas inclusivas.

A concepção de alguns professores de LI que trabalham em escolas inclusivas indica não apenas falta de conhecimento da Libras e da cultura surda, mas a visão de que a L1 do surdo não é uma língua natural e, portanto, não tem o mesmo prestígio linguístico que as demais línguas. Essa concepção pode propiciar um ambiente educacional onde a L1 do surdo assuma um caráter subtrativo, isto é, a L3 é adquirida com prejuízo da L1 do aluno surdo, conforme é apresentado no trabalho de Silva e Hübner (2015). A aquisição da L3 com prejuízo da L1 pode ocorrer quando houver preconceito linguístico em relação a essa última (LS), ou seja, quando houver desvalorização da L1 do surdo e prestígio da língua oral majoritária como a LP ou LI. Segundo Lambert (1977), essa situação configura o que o autor denominou de Bilinguismo Subtrativo, em que as línguas que interagem no ambiente escolar não são vistas como entidades complementares e igualmente necessárias; e sim, onde uma língua é considerada superior à outra. Nessa situação, o aluno surdo pode ser conduzido a pensar que sua L1 é socialmente inferior à L2 ou L3. Portanto, cabe aos professores valorizarem a LS, destacando que essa língua tem o mesmo status linguístico da LP ou da LI que eles estão aprendendo, ou seja, os alunos surdos devem aprender a L2 ou L3, sem prejuízo de sua L1, configurando o que Lambert (1977) denominou de Bilinguismo Aditivo. Dessa forma, evitam-se antigos conceitos que fazem parte da história da educação de surdos no Brasil, na qual havia um desprestígio em relação à língua de sinais. Naquele cenário, conforme Brito (2010), ocorria a concepção, por parte dos alunos surdos, de que as línguas orais constituíam uma ameaça à sua língua materna.

A falta de proficiência linguística na LS por parte dos professores que ensinam LI para surdos é uma realidade em muitas escolas de educação inclusiva. Esse fator em si não impede que o professor ministre suas aulas, pois a presença dos intérpretes de Libras na sala de aula é prevista em lei, e o papel desse profissional é fazer a mediação entre professor e aluno. Contudo, o conhecimento da língua materna do aluno surdo aproxima o professor e o aluno; conhecer a LS do surdo estabelece um vínculo que pode promover e motivar os educandos a aprender a L2 ou a L3.

A seção seguinte tratará sobre as implicações pedagógicas envolvendo o ensino de LI como L3 para estudantes surdos.

\section{A PARTIR DOS DESAFIOS EXISTENTES NO PROCESSO DE ENSINO-APRENDIZAGEM DA LI (L3) POR SURDOS, QUAIS AS IMPLICAÇÕES PEDAGÓGICAS PARA O ENSINO DESSES SUJEITOS?}

O fato de não termos as condições ideais para o ensino-aprendizagem da LI para surdos em termos de materiais e de formação específica dos professores faz com que muitos educadores e profissionais que trabalham na área da educação de surdos se dediquem a pensar em formas de suprir as lacunas existentes. Essa reflexão e adequação é fundamental, pois os achados de pesquisas revelam que há grandes diferenças no bilinguismo entre sujeitos surdos e ouvintes aprendendo uma L3 oral, como já mencionado.

Conforme destaca Peixoto ${ }^{6}(2006,2015)$, diferentemente do ouvinte, o surdo não fonetiza a escrita, ou seja, não faz relação sonora com o sistema da L2 (ou L3), apoiando-se no único recurso que têm à sua disposição, ou seja, os aspectos visuais da língua escrita que está aprendendo. Assim, na tarefa de aprender uma língua adicional, na forma escrita, são os elementos viso-espaciais como a forma das letras, o espaço e a linearidade na construção das palavras e frases a que o surdo recorre e relaciona com sua LS para tornar a aprendizagem significativa. Logo, na prática docente é fundamental que os professores, seja de L2 ou L3, utilizem e esgotem todas as possiblidades visuais da língua-alvo, relacionando-a com a LS do surdo.

De fato, existe a possibilidade de aproximar a LS da língua oral na forma escrita (L2, L3), ainda que sejam línguas de modalidades diferentes. Pesquisadores como Cummins (1981), Gesueli (2006) e Peixoto (2006, 2015) defendem que se a LS for bem estabelecida,

\footnotetext{
${ }^{6}$ Em sua pesquisa, Peixoto $(2006,2015)$ está se referindo a surdos com surdez severa-profunda, e não a surdos com surdez leve ou moderada, os quais podem, por meio de fonoterapia, conseguir fazer relações entre letras e sons.
} 
poderá haver transferência tanto de seus elementos linguísticos como de habilidades metalinguísticas e metacognitivas necessárias para a compreensão da L2.

O aprendiz surdo de LI com terceira língua já é usuário de sua LS e tem conhecimento da LP, assim o professor de LI deve se valer dessas experiências linguísticas anteriores, aproximando a LI da LS tanto quanto possível. As pesquisas acima enfatizam o papel fundamental da LS (L1) do surdo, pois ela é a base sobre a qual as outras línguas serão aprendidas. Ou seja, mesmo que a LS e a LI sejam de modalidades diferentes, a LS constitui um facilitador para a apropriação da língua adicional.

A aproximação da LS com a LI é feita por meio dos pontos em comum entre essas línguas, por exemplo, relacionando o alfabeto manual, que é a transformação das letras do alfabeto na Configuração de Mão $\left(\mathrm{CM}^{7}\right)$ da LS, com a letra inicial da palavra em LI. Cabe aos professores, quando possível, utilizar essa estratégia útil para o ensino da LI escrita. A pesquisa de Silva e Hübner (2015), investigando possíveis transferências léxico-semânticas entre a LS e a LI, identificou a tentativa dos informantes em relacionar a LS com a LI. Em um dos testes aplicados, os alunos visualizavam o sinal em Libras e deveriam selecionar a palavra em LI equivalente ao sinal. Nos resultados foram encontradas as opções yellow para "avião" e leg para "livro", para citar alguns exemplos. A seleção yellow indica que o surdo utilizou a letra inicial Y, letra que tem a mesma CM (Y) do sinal AVIÃO em LS. Da mesma forma, a seleção de leg para o sinal LIVRO evidencia esse fato, pois a letra inicial de leg $(\mathrm{L})$ apresenta a mesma CM (L) do sinal LIVRO. A proximidade visual entre a Libras e a LI são estratégias, em geral, bem-sucedidas e devem ser exploradas pelos professores de LI. É importante destacar que mesmo quando a comparação visual entre a LS e a LI não é possível, essa estratégia é válida, pois estimula as habilidades metalinguísticas e metacognitivas dos estudantes surdos.

Outra consideração relevante para os professores de LI é a presença da Libras na leitura ou escrita de palavras em LI. A transferência da L1 para a L2 ou L3 é um fenômeno natural na aquisição de novos sistemas linguísticos, ainda que sejam línguas de modalidades diferentes, conforme Silva e Hübner (2015). Cappovilla e Raphael (2001) analisaram pares de palavras semelhantes quiremicamente $^{8}$ (fonologicamente) em Libras, como sábado-aprender ${ }^{9}$, que, por serem similares do ponto de vista fonológico, podem apresentar dificuldades para surdos aprendizes de uma língua oral no meio escrito. Segundo Cappovilla e Raphael ${ }^{10}$ (2001), muitas vezes, os erros de leitura e escrita do surdo são decorrentes da mediação da Libras, pois ela está ativa e interagindo com a L3. Em uma das tarefas do estudo de Silva e Hübner (2015), foi aferido o tempo que os alunos utilizavam para responder se os pares de palavras eram semanticamente semelhantes ou não. Como resultado, foi observado que mesmo nos pares sem relação semântica como TV-work, house-ship, wine-pink (mas relacionados quiremicamente) foi necessário um tempo maior para responder. Semelhanças de ordem quirêmica demandam mais tempo para serem processadas e isso se reflete sobre o tempo de resposta do aluno, como se o surdo necessitasse analisar diferentes possibilidades em sua língua materna. Esse fato indica que a LS está presente no processo de aquisição de uma L3, pelo menos na fase inicial de aprendizagem da L3, e provavelmente, por isso o aluno surdo comete erros de leitura ou escrita que os ouvintes não fazem. Esses dados podem ser úteis para os professores planejarem suas aulas, antecipando futuras dificuldades ou facilidades que apenas alunos surdos tendem a apresentar na aquisição de línguas adicionais.

\footnotetext{
${ }^{7}$ As CMs têm caráter distintivo e constituem fonemas nas línguas de sinais. Elas são alguns dos parâmetros fonológicos constitutivos das LS, são as formas feitas nas mãos ou a disposição dos dedos que a mão apresenta. Muitas vezes há equivalência entre a CM do sinal e a letra inicial da palavra em LP/LI, mas essa semelhança nem sempre se verifica. A fonologia nas LS não se refere aos sons da língua, mas às unidades mínimas (sem significado) que constituem os sinais. Vale destacar que além das CMs, existem outras unidades fonológicas que constituem os sinais, como o Ponto de Articulação, o Movimento (denominados de parâmetros primários), as Expressões não Manuais e a Orientação das Palmas das Mãos (denominados parâmetros secundários). Como destacam Quadros e Karnopp (2004), assim como as línguas orais apresentam alofones, que são as realizações variadas de um mesmo fonema, as LS igualmente podem apresentar alofones, sem que haja mudança de significado. Por exemplo, em LIBRAS, o sinal de TREINAR pode ser produzido com duas configurações diferentes dependendo de quem sinaliza, ou seja, na parte de cima do braço, e na parte de baixo do braço, sem mudança de significado.
}

\footnotetext{
${ }^{8}$ Semelhança quirêmica (fonológica) nas LS refere-se à presença de elementos em comum entre sinais com os parâmetros (traços) que os constituem. Os traços quirêmicos das LS equivalem aos fonemas das línguas orais. Como parâmetros na LIBRAS temos: Configuração de Mão (CM), Movimento (M), Ponto de Articulação (PA), Orientação (Or), Expressão não Manual (ENM).

${ }^{9}$ Os sinais em LIBRAS equivalentes às palavras sábado e aprender são muito semelhantes, pois eles possuem a mesma CM, Or, M, ENM, diferindo-se apenas no parâmetro PA.

${ }^{10}$ A mediação da LIBRAS na aquisição da LP ou LI não significa que ela interfere negativamente no processo de aquisição dessas línguas. A presença na língua materna nos estágios iniciais da L2 ou L3 é um fenômeno natural no processo da aquisição multilíngue.
} 
Tendo-se este fato em mente, percebe-se, como já mencionado, o caráter facilitador de lidar com o processo de literacia - conceito a ser especificado abaixo - em L2 e L3 pelos aprendizes surdos do conhecimento da Libras pelo professor.

Outro elemento relevante que o professor deve considerar para o ensino de LI são as palavras ortograficamente semelhantes entre a LI e LP. No processo inicial de aquisição da LI, alunos com nível de proficiência básico em LP podem incorrer em erros ortográficos que evidenciam a falta de distinção entre esses dois sistemas. Silva e Hübner (2015) demonstram que os aprendizes surdos de LI, ao serem solicitados a escrever a palavra "arm", escreviam "arma” e para "homework”, escreviam "homem”. Essas produções confirmam a tese de Cummins (1981) da transferência entre as línguas que possuem o mesmo sistema alfabético na forma escrita, nesse caso da LP para a LI. O surdo que escreve "homem" em vez de "homework" se baseia nos aspectos ortográficos dessas palavras que, por apresentarem semelhanças gráficas, podem favorecer transferências entre as línguas. Supõe-se que a visualização ortográfica de palavras em LI que se assemelhem a palavras em LP, seja na presença de letras em comum, seja em segmentos silábicos similares, contribui para que o aluno transfira palavras da LP para a LI e vice-versa.

Outra reflexão relevante para professores são os pares de palavras semelhantes ortograficamente como perto-preto em LP. A pesquisa de Silva e Hübner (2015) igualmente identificou trocas ortográficas de alunos aprendendo LI. Nesse estudo, houve um maior índice de erros nos pares ortograficamente similares como (teacher-theater), (book-door), ou na inversão de letras (huose em vez de house), (chari para chair) em tarefas de produção escrita. Esses dados revelam que o surdo memoriza as palavras em sua globalidade, como um sistema ideográfico, sem o apoio da fonologia da LI, e portanto, pode incorrer em produções escritas que são exclusivas de surdos como buel para blue, bkie para bike e shool, schloo para school. Esses resultados mostram que o surdo percorre um caminho que não se fundamenta na relação da escrita com a oralidade. Incorreções dessa natureza, segundo Gesueli (2006), indicam a relevância do visual para o surdo, que memoriza algumas letras que formam as palavras, principalmente o aluno em fase de aquisição inicial da língua escrita (LI). Evidências como estas demonstram que o aprendiz surdo não aprende pela correlação grafema-fonema, como ocorre com os ouvintes, e sim, que se vale de outras estratégias, de cunho visual e/ou com base na Libras para aprender a escrita e a leitura de palavras em línguas orais no meio escrito.

Refletindo sobre as características do aprendiz surdo, como a importância dos aspectos visuais para seu aprendizado, vale destacar que os professores devem utilizar as imagens e os recursos visuais como elementos essenciais no processo de construção do conhecimento de seus alunos. Dada a relevância da imagem e da visualidade, o professor de LI deve pautar suas estratégias de ensino em uma alfabetização visual, explorando ao máximo esses aspectos na leitura-escrita da LI como a forma das letras, a relação com a CM da Libras com a letra inicial da palavra em LI, quando houver e, se possível, as semelhanças gráficas com a LP. Diversos pesquisadores destacam a importância do ensino visual para o aluno surdo e denominam de Alfabetização Visual, como propõe Gesueli (2006), o ensino que tenha por base a visualidade na educação desses sujeitos.

Para tanto, há a necessidade de se desenvolverem (ou adaptarem) materiais educacionais específicos para que o ensinoaprendizagem da LI se realize satisfatoriamente. Materiais educacionais voltados a alunos surdos devem apresentar uma abordagem diferente daquela presente nos materiais produzidos para alunos ouvintes. As habilidades de fala (speaking) e audição (listening) não devem ser apresentadas, mas podem ser substituídas pela exploração dos aspectos visuais em textos e palavras em LI. Todas as atividades pedagógicas dos professores devem estar voltadas para o desenvolvimento das habilidades de leitura (reading) e escrita (writing), e o emprego de estratégias de ensino que respeitem a realidade sensorial do aluno surdo.

Vale mencionar que, para o ensino da LP, o Decreto $n^{\circ}$ 5.626/2005 determina que essa língua deve ser ministrada na forma escrita no horário escolar, e a oralidade em LP deverá ser ministrada no contraturno para os alunos e/ou famílias que tenham interesse. Esse trabalho em turno distinto ao da escolarização ocorrerá por meio de ações integradas entre instituições e profissionais da área da saúde, como o fonoaudiólogo. Analogamente, espera-se que com a língua inglesa seja adotado o mesmo procedimento no currículo escolar, no qual a LI seja ministrada na forma escrita, em uma perspectiva funcional e instrumental, não sendo trabalhada a oralidade nas aulas de LI para surdos.

Logo, não parece fazer sentido os professores pautarem o ensino na correspondência entre fonema-grafema em sua prática docente, pois, como a surdez reduz ou priva o sujeito do acesso à oralidade, são os aspectos visuais das línguas escritas que devem ser utilizados 
como estratégias pedagógicas eficazes, como já mencionado acima. O trabalho de associação grafema-fonema para surdos pode ter validade em situações de clínica, em casos específicos, levando em consideração fatores como, por exemplo, o grau de surdez do indivíduo; no entanto, na relação ensino-aprendizagem de sala de aula deve-se optar pela ênfase em estratégias visuais.

A partir deste ponto, entra-se em uma discussão sobre a literacia ${ }^{11}$. Segundo Morais (2019), a literacia engloba a linguagem letrada em três sentidos: o primeiro é a capacidade de ler e escrever palavras de modo automático; o segundo é

[...] a capacidade (cognitiva, estética, intencional e participativa) de utilizar essas habilidades para adquirir conhecimentos, examinar criticamente os conhecimentos existentes, criar outros conhecimentos e transmitilos, sentir e transmitir beleza, emoções, valores, e, indo mais além, desenvolver a linguagem, mas também capacidades cognitivas como a percepção, a atenção, a memória, o raciocínio, e utilizar tudo isso para prazer pessoal e participação ativa na sociedade. (MORAIS, 2019, p. 10)

Finalmente, o terceiro sentido da palavra literacia refere-se à competência nos diferentes domínios/áreas de literacia, como a "científica, literária, informática ou digital, de saúde, da mídia, financeira etc" (p. 10). Vale acrescentar que a literacia, segundo Morais (2019) e outros autores como Ardilla et al., (2010), Sousa e Hübner (2017) está intrinsicamente relacionada a fatores socioeconômicos e de hábitos de leitura e escrita de uma população, desenvolvidos também além dos anos de ensino formal, visto que a literacia tende a ser fortalecida e ampliada em contextos culturais mais abastados e/ou em situações em que o indivíduo interage ricamente com material escrito.

No caso do aprendiz surdo, o acesso a esses bens culturais veiculados pela língua escrita na LP, são, portanto, essenciais para que ele consiga ampliar sua literacia. Desse modo, a linguagem letrada tem um impacto no pensamento e na racionalidade, bem como no pensamento livre e crítico, necessário para um pensamento justo, preciso e produtivo (MORAIS, 2019, p. 9). ${ }^{12}$ Do mesmo modo, ou seja, não apenas nas línguas adicionais na forma escrita, mas também em sua L1 (Libras), o acesso a uma literacia mais ampla deve ser disponibilizado e garantido, visto que o conceito de literacia não se restringe a línguas alfabéticas, incluindo outras, como a língua de sinais, como destaca Morais (2019).

Os recursos didáticos produzidos devem aproximar a LI da Libras, valorizando as experiências pessoais dos alunos, com a introdução de novos conteúdos de maneira contextualizada. Os materiais utilizados pelos professores podem destacar a relação entre palavra em LI e a imagem a ela relacionada, pois, muitas vezes, o aluno, por não ter acesso à oralidade, não relaciona a palavra escrita ao significado que ela expressa. A utilização de recursos visuais como fotografias, filmes, objetos concretos, revistas, desenhos auxiliam na compreensão e construção do conhecimento em uma língua adicional. As novas tecnologias estão cada vez mais presentes no cotidiano das pessoas, e os professores podem utilizá-las como instrumentos educacionais que promovam e facilitem o ensino. Para tanto, deve-se enfocar a visualidade da LI escrita como no uso da internet, em jogos interativos digitais, na projeção recursos digitais por data show, em mostras de vídeos do youtube, em gravação de vídeos feitos pelos alunos, assim como nas redes sociais, nos aplicativos e em outras ferramentas tecnológicas e educacionais, bem como o ensino no qual a interdisciplinaridade entre os componentes escolares possa ocorrer.

Vale destacar que no contexto escolar onde interagem três línguas é necessário que seja proporcionado aos alunos um ambiente em que todas as línguas tenham seu prestígio linguístico assegurado, bem como a cultura de cada comunidade linguística. As línguas não devem competir entre si ou apresentar ameaças umas às outras, mas possuir o mesmo prestígio linguístico. A Libras como L1 é a língua de identificação do surdo e a língua da comunicação entre seus pares, enquanto a LP (na escrita) como L2 representa o meio de o surdo ter acesso à informação e ao conhecimento compartilhados na língua oral majoritária. A LI (escrita), como língua majoritária na globalização, permite ao surdo estar inserido em um mundo globalizado, tendo acesso a informações veiculadas e

\footnotetext{
${ }^{11} \mathrm{O}$ termo literacia distingue-se conceptualmente dos termos "letramento" e ‘alfabetização" por compreender uma visão mais abrangente que a dos dois termos anteriormente empregados, como pode ser verificado ao se analisar a complexidade da definição proposta por Morais (2019), acima, para explicar os diferentes domínios que o termo abrange.

${ }^{12}$ Importante frisar que, no caso das línguas ágrafas e da própria LIBRAS, que comumente não é representada em sua versão escrita, o acesso à literacia na LP pode ser uma ferramenta complementar para facilitar a organização do pensamento e do raciocínio, além de representar mais uma porta de acesso ao conhecimento em diferentes áreas, visto que grande parte do conhecimento é veiculado nas diferentes línguas orais pela escrita, de forma impressa ou digital.
} 
compartilhadas nessa língua, bem como ampliando suas possibilidades de sucesso acadêmico e profissional. É importante salientar que quem ensina uma língua também ensina a cultura dessa língua. No cenário escolar, o estudante surdo precisa ter assegurada a valorização de sua LS, bem como a cultura da comunidade surda na qual ele está inserido.

\section{CONSIDERAÇÕES FINAIS}

No presente artigo, foram apresentadas questões referentes à aquisição bi/multilíngue do aprendiz surdo como as características do bilinguismo intermodal, desafios para a aquisição de uma L3 de modalidade oral, bem como reflexões e sugestões para uma prática pedagógica que contemple as particularidades desses educandos.

Em nosso país, embora a Libras tenha sido oficializada pela Lei no 10.436 (BRASIL, 2002) e regulamentada no Decreto $\mathrm{n}^{\circ} 5.626$ (BRASIL, 2005), são raros os trabalhos que investigam a aquisição multilíngue do aluno surdo. Embora escassas, as pesquisas sobre a aquisição de línguas adicionais (L3) por esses sujeitos revelam dados significativos para professores e profissionais que trabalham com alunos surdos aprendizes de um terceiro sistema linguístico. As investigações na área da aquisição de língua(s) adicional(is) para surdos indicam a importância do aspecto visual como recurso pedagógico que deve ser explorado no ambiente escolar. Da mesma forma, dados de pesquisas como as de Cummins (1981), Gesueli (2006) e Peixoto $(2006,2015)$ mostram a relevância da língua materna para o aprendizado de outras línguas de escrita alfabética como a LP e a LI, pois ela é a base sobre a qual as outras línguas podem ser aprendidas. Desse modo, a LS poderá se relacionar com outras línguas, havendo possibilidade de aproximá-la da LS da LI, mesmo que essas línguas não compartilhem a mesma modalidade.

As transferências linguísticas encontradas em estudos que investigaram a aquisição de LI por surdos em contexto multilíngue brasileiro fornecem dados que podem auxiliar os professores, como a confirmação de que pode haver transferências interlinguísticas entre línguas de modalidades diferentes e que essas transferências podem ocorrer no sentido da Libras para a LI, ou da LP para a LI. Demonstrou-se, igualmente, a importância dos aspectos gráficos das palavras escritas em LP e LI como fator que auxilia o aprendizado do aluno, assim como o papel da semelhança quirêmica (fonológica) dos sinais na leitura de palavras em LI.

Os achados dessas pesquisas são significativos para profissionais que trabalham com sujeitos surdos aprendizes de línguas adicionais como a LP, a LI, e igualmente a língua espanhola, ministrada em muitas instituições de ensino em nosso estado como L3 para alunos surdos.

Após a apresentação dos resultados das pesquisas aqui relatadas, conclui-se que antes de se efetivar o ensino de uma L3 para o aluno surdo é necessário que o professor tenha em mente as especificidades da aquisição de línguas por esses aprendizes. As concepções pedagógicas devem partir das características linguísticas do surdo bi/multilíngue intermodal, que trilha uma trajetória diferente daquela do aprendiz ouvinte de línguas orais. Os caminhos percorridos pelos aprendizes surdos rumo à leitura-escrita - à literacia na LI como L3 revelam que não podemos nos valer de práticas tradicionais e/ou de modelos pedagógicos que são úteis para a realidade de alunos ouvintes.

As pesquisas realizadas sobre a aquisição de línguas adicionais por surdos, ainda que iniciais, nos apontam a direção, ou seja, um novo olhar sobre a literacia do sujeito surdo que valorize a sua LS e a correlacione com a L2 e a L3 que está aprendendo, considerando que a aprendizagem do surdo é sempre uma experiência visual. 


\section{REFERÊNCIAS}

ARDILA, A. et al. Illiteracy: the neuropsychology of cognition without reading. Archives of Clinical Neuropsychology, v. 25, p.689712, 2010.

ASSEMBLEIA LEGISLATIVA,

$17 / 9 / 19$

acessado

em

http://www.al.rs.gov.br/agenciadenoticias/destaque/tabid/855/Default.aspx?IdMateria=318300

BASTOS, A. P.; HÜBNER, L. C. Influência translinguística na aprendizagem de inglês por surdos. The Especialist, v. 41, n. 1, 2020.

BLANK, C.; ZIMMER, M. A transferência fonético-fonológica L2 (francês) - L3 (inglês): um estudo de caso. Revista Estudos da Linguagem, Belo Horizonte, v.17, n. 1, p. 207-233, jan./jun. 2009.

BRASIL. Decreto $n^{\circ} 5.626$, de 22 de dezembro de 2005. Regulamenta a Lei n 10.436 , de 24 de abril de 2002, que dispõe sobre a Língua Brasileira de Sinais - Libras, e o art. 18 da Lei no 10.098, de 19 de dezembro de 2000. Brasília, 2005.

BRASIL. Lei Federal n 10.436, de 24 de abril de 2002. Dispõe sobre a Língua Brasileira de Sinais - Libras e dá outras providências. Brasília, 2002.

BRASIL. Lei n 9.394, de 20 de dezembro de 1996. Estabelece as diretrizes e bases da educação nacional. Brasília, 1996.

BRASIL. Medida Provisória $n^{\circ}$ 746, de 22 de setembro de 2016. Altera a Lei no 9.394, de 20 de dezembro de 1996, que estabelece as diretrizes e bases da educação nacional, 2016.

BRITO, R. C. de C. Representações do professor de língua inglesa no ensino inclusivo dos alunos surdos. 2010.167 f. Dissertação (Mestrado em Estudos Linguísticos) - Faculdade de Letras, Universidade Federal de Minas Gerais, Belo Horizonte, 2010.

CAPOVILLA, F. C.; RAPHAEL, W. D. (ed.). Dicionário enciclopédico ilustrado trilíngue da língua de sinais brasileira. 2. ed. São Paulo: EDUSP, 2001.2 V.

CENOZ, J. Research on multilingual acquisition. In: CENOZ, J.; JESSNER, U. (ed.). English in Europe. The acquisition of a third language. Clevedon: Multilingual Matters, 2000. p. 39-53.

COURA, F. A. Inglês na palma da mão: Letramento crítico e ensino de Inglês para alunos surdos. 2016. 172 f. Dissertação (Mestrado em Letras) - Faculdade de Letras da Universidade Federal de Minas Gerais, Belo Horizonte, 2016.

CUMMINS, J. The role of primary language developmentin promoting educational success for language minority students. In: LEYBA, C. F. (ed.). Schooling and language minority students: a theoretical framework. Los Angeles, USA: State Department of Education, 1981.p. 3-49.

GESUELI, Z. M. Lingua(gem) e identidade: a surdez em questão. Educ. Soc. Campinas, v.27, n. 94, p. 277-292, jan./abr. 2006 GROSJEAN, F. Living with two languages and two cultures. In: PARASNIS, I. (ed.). Cultural and language diversity and the deaf experience. Cambridge: Cambridge University Press, 1996. p. 20-37.

KRASHEN, S. D. Principles and practice in second language acquisition. Oxford: Pergamon Press, 1982.

LAMBERT, W. E. The effects of bilingualism on the individual: cognitive and sociocultural consequences. In: HORNBY, P. A. (ed.). Bilingualism: psychological, social and educational implications. New York: Academic Press, 1977. p. 15-27. 
MEDEIROS, T. G. Concepções de professores de inglês e intérpretes diante das políticas educacionais inclusivas e a prática de inglês para alunos surdos. 2011. 143 f. Dissertação (Mestrado em Letras e Linguística) - Faculdade de Letras, Universidade Federal de Goiás, Goiânia, 2011.

MORAIS, J.. O que faz a diferença entre a linguagem rica e a pobre?. Signo, Santa Cruz do Sul, v. 44, n. 81, p. 02-21, set. 2019. ISSN 1982-2014. Disponível em: https:/online.unisc.br/seer/index.php/signo/article/view/14574. Acesso em: 19 abr. 2020.

OLIVEIRA, D. F. A. Professor, tem alguém ficando para trás!: as crenças de professores influenciando a cultura de ensino/aprendizagem de LE de alunos surdos. 2007. 240 f. Dissertação (Mestrado em Linguística Aplicada) - Instituto de Letras, Universidade de Brasília, Brasília (DF), 2007.

PEIXOTO, R. C. Algumas considerações sobre a interface entre a Língua Brasileira de Sinais (LIBRAS) e a língua portuguesa na construção inicial da escrita pela criança surda. Cadernos Cedes, Campinas, v. 26, n. 69, p. 205-229, maio/ago. 2006.

PEIXOTO, R. C. Ensino de português para surdos em contextos bilíngues: análise de práticas e estratégias de professoras ouvintes nos anos iniciais do ensino fundamental. 2015. 284f. Tese (Doutorado) - Programa de Pós-graduação em Educação Brasileira, Universidade Federal do Ceará, Fortaleza, 2015.

PEREIRA, K. A. O ensino de língua estrangeira na educação de surdos: recontextualização dos discursos pedagógicos em práticas de professores de alunos surdos. 2015. 234 f. Tese (Doutorado em Educação) - Faculdade de Educação, Universidade Federal de Pelotas, Pelotas, 2015.

PERLIN, G. T. T. Identidades surdas. In: SKLIAR, C. (org.) A surdez: um olhar sobre as diferenças. Porto Alegre: Mediação, 1998.

PLAZA PUST, C. Sign bilingual education and inter-modal language contact: on the relation of psycholinguistic and pedagogical factors in deaf bilingualism. In: INTERNATIONAL SYMPOSIUM ON BILINGUALISM, 4 ${ }^{\text {th }}$ 2005, Somerville, MA. [Proceedings...]. Somerville, MA: Cascadilla Press, 2005. p. 1842-1854.

QUADROS, R. M. Educação de surdos: a aquisição da linguagem. Porto Alegre: Artes Médicas, 1997.

QUADROS, R. M. de; KARNOPP, L. Língua de sinais brasileira: estudos lingüísticos. ArtMed: Porto Alegre, 2004.

QUADROS, R.; LILLO-MARTIN, D.; CHEN PICHLER, D. Bilinguísmo e Bimodalismo Desenvolvimento Bilíngue Intermodal. In: CONGRESSO INTERNACIONAL E XV SEMINÁRIO NACIONAL DO INES, 9., 2010. Anais... Rio de Janeiro: Editora do INES, 2010. p. 146-150.

RUBIO, A. C. F. Ensino de língua estrangeira e inclusão: percepções de alunos com surdez ou com deficiência auditiva sobre as aulas de inglês em escolas regulares. 2010. 140 f. Dissertação (Mestrado em Linguística) - Centro de Ciências Humanas, Universidade Federal de São Carlos, São Carlos, 2010.

SILVA, M. C. C.; HÜBNER, L. C. Aprendizagem da Língua Inglesa como terceira língua (L3) por aprendizes surdos brasileiros: investigando a transferência léxico-semântica entre línguas de modalidades diferentes. Veredas, Juiz de Fora (MG), v. 19, n. 2, p. 34 $47,2015 / 2$.

SOUSA, Aline N. Educação plurilíngue para surdos: uma investigação do desenvolvimento da escrita em português (segunda língua) e inglês (terceira língua). 2015. 384 f. Tese (Linguística Aplicada) - Programa de Pós-Graduação em Linguística, Universidade Federal de Santa Catarina. Florianópolis, 2015. 
SOUSA, L.; HÜBNER, L. A relação entre desempenho em compreensão leitora e fatores socioeconômicos. Fórum Linguístico, Florianópolis, v. 14, n. 2, p. 2044-2060, jun. 2017. Disponível em: https://periodicos.ufsc.br/index.php/forum/article/view/1984$\underline{8412.2017 \mathrm{v} 14 \mathrm{n} 2 \mathrm{p} 2044}>$. Acesso em: 19 abr. 2020.

TAVARES; K. C. A.; OLIVEIRA, A. P. P. O. Libras no ensino de inglês mediado pelas novas tecnologias: desafios e possibilidades. Revista Brasileira de Linguística Aplicada, v. 14, n. 4, 2014.

\section{(๑) $\circledast$}

Recebido em 20/04/2020. Aceito em 16/07/2020. 